Artigo de Revisão

\title{
Dor e depressão
}

\section{Chronic Pain and Depression}

\author{
Manoel Jacobsen Teixeira ${ }^{1}$
}

\section{RESUMO}

Dor crônica é condição dispendiosa e clinicamente debilitante. É considerada como um fenômeno biopsicossocial. A dor crônica inclui uma grande variedade de condições clínicas bastante heterogênias. Os programas de reabilitação sem a participação de reabilitação na área de saúde mental proporcionam resultados insatisfatórios. A psicopatologia pode também aumentar a intensidade da dor e da incapacidade e pode perpetuar a disfunção relacionada a dor. Muito desse interesse se deve ao fato de elevada freqüência com que doentes com dor crônica sofrem depressão. Relação temporal entre essas anormalidades pode variar: a depressão pode preceder a ocorrência da dor crônica, ser conseqüência da dor crônica ou pode ser um evento biológico concomitante com a dor crônica. Ao mesmo tempo os fenômenos psicopatológicos intensificam a experiência dolorosa. A relação entre a dinâmica e o reforço entre dor psicopatologia torna impossível tratamento de cada condição independentemente de outra.

\section{Unitermos: Antidepressivo; Depressão; Dor.}

Citação: Teixeira MJ. Dor e depressão. Rev Neurocienc 2006; 14(2):044-053.

\section{SUMMARY}

Chronic pain is an increasingly costly and debilitating medical condition. It is widely viewed as a biopsychosocial phenomenon. Chronic pain includes a large variety of heterogeneous clinical conditions. Rehabilitation programs without an adequate mental health component may therefore become a failure. Psychopathology may also increase pain intensity and disability, thus serving to perpetuate pain-related dysfunction. Anxiety has been found to decrease pain threshold and tolerance, anxiety and depression have been associated with magnification of medical symptoms, depression has been associated with less successful treatment outcomes, and emotional distress has been linked to physical symptoms through autonomic arousal, vigilance, and misinterpretation or somatic amplification. Much of this interest can be attributed to the high frequency with which chronic pain patients suffer from depression. There is no single explanation that can be generalized to all individuals. What does seem certain in almost all cases is that there a prepay vulnerability to a certain type of psychopathology, or a more generalized vulnerability to psychopathology, that may or may not have reached the level of diagnosable psychopathology before the onset of pain. The dynamic and reinforcing interplay between pain and psychopathology make it impossible to treat either condition independently of the other.

\section{Keywords: Antidepressive Agents; Depression; Pain.}

Citation: Teixiera MJ. Chronic pain and depression. Rev Neurocienc 2006; 14(2):044-053.

\section{INTRODUÇÃO}

Dor é o sintoma que mais freqüentemente induz procura por assistência'. Em 1979, uma comissão da Associação Internacional para o Estudo da Dor (IASP) conceituou dor como "experiência sensitiva e emocional desagradável associada a lesões reais ou potenciais ou descrita em termos de tais lesões. A dor é sempre subjetiva e cada indivíduo aprende a utilizar o termo baseando-se em suas experiências pessoais frente a lesões que ocorrem desde o início da vida"2. Este conceito dispensa a necessidade de existência de lesão e enfatiza a subjetividade na interpretação do fenômeno como seu caráter emocional e sensitivo. A dor induz a anormalidades físicas e altera o equilíbrio psicológico de quem a sofre. A dor aguda é aquela que desaparece assim que ocorre cura da lesão causal. A dor crônica é a que apresenta duração superior a um mês -, três meses -ou seis meses - ou que persiste além do período esperado para cura da lesão causal ou a que se associa a doenças naturalmente crônicas ${ }^{3,4}$.

Apesar de haver relação entre dor e depressão, e da depressão ser diagnóstico psiquiátrico comum em doentes com afecções clínicas, freqüentemente, esta não é identificada e conseqüentemente não tratada; pois podem ocorrer semelhanças entre os sintomas das doenças e da depressão ${ }^{5}$. 


\section{Fisiopatologia da dor}

O primeiro passo na seqüência dos eventos que originam o fenômeno sensitivo doloroso é a transformação pelos receptores ou terminações nervosas livres (nociceptores) dos estímulos ambientais térmicos, mecânicos e ou químicos intensos em potenciais de ação que, das fibras nervosas amielínicas do grupo $\mathrm{C}$ ou mielinizadas finas $A-\delta$ do sistema nervoso periférico (SNP), são transferidos para o sistema nervoso central (SNC). Quando ocorre inflamação prolongada ou lesão nervosa, os nociceptores são sensibilizados pelo acúmulo de prótons, íons $\mathrm{K}^{+}$, péptides, lípides, acetilcolina, bradicinina, histamina, serotonina (5-HT), leucotrienos, substância P (sP), fator de ativação plaquetário, purinas, radicais ácidos, óxido nítrico (NO), prostaglandinas (PGs), tromboxanas, trifosfato de adeniosina, citocinas e adenosina monofosfato cíclica liberados em conseqüência da vasodilatação, da ativação de monócitos, macrófagos, mastócitos, fibroblastos, linfócitos, células endoteliais, ceratinócitos, fibras musculares lisas e células traumatizadas. A sP, as neurocininas $\mathrm{A}$ e $\mathrm{B}$ e o peptídio relacionado geneticamente à calcitonina (PGRC), entre outros, são liberados nos tecidos pelas terminações nervosas dos aferentes nociceptivos e interagem com elementos celulares envolvidos no processo inflamatório (neutrófilos, linfócitos, plasmócitos, macrófagos) ou regenerativo (fibroblastos, células de Schwann, endotélio vascular) atraindo-os ou ativando-os, gerando vasodilatação e instalação de processo inflamatório de origem neurogênica (inflamação neurogênica) ${ }^{6}$. Os neurônios dos gânglios sensitivos e as fibras nervosas periféricas são também sensibilização dos aferentes e dos receptores causa redução do limiar da dor (hiperalgesia) e torna os estímulos mecânicos e térmicos dolorosos (alodínea).

Os aferentes nociceptivos penetram na medula espinal preferencialmente pelas raízes posteriores e projetamse especialmente nas lâminas I e V do corno posterior da substância cinzenta da medula espinal (CPME) ${ }^{7}$. A ativação dos neurônios da coluna intermediolateral resulta em hiperatividade das vias neurovegetativas simpáticas periféricas induzindo anormalidades neurovegetativas regionais e hipertonia muscular, conseqüente a ativação dos neurônios da ponta anterior da substância cinzenta da medula espinal. Glutamato, aspartato, 5-HT, dopamina, tirosina, adenosina, sP, substância $\mathrm{K}$, octapeptídeo-colecistocinina, somatostatina, PGRC, peptídeo vasoativo intestinal, neuropetídeo Y, dinorfina, encefalinas, fator de liberação de corticotrofina, arginina, vasopressina, oxitocina, peptídeo liberador de gastrina, bombesina, angiotensina II, galanina e fator de crescimento de fibroblastos atuam como neurotransmissores nas fibras aferentes primárias ${ }^{8}$. Estímulos fracos e moderados liberam pequena quantidade de glutamato e de sP que despolarizam a membrana neuronal e geram sensação de dor momentânea. Quando a estimulação é intensa e prolongada há sensibilização dos neurônios do CPME o que gera (alodínea) mecânica e hiperalgesia secundárias . Receptores ativados pelo ácido 2-amino3-hidroxi-5-metil-4-isoxasol-propiônico e cainato são acionados imediatamente após a liberação de glutamato e causam influxo de $\mathrm{Na}^{+}, \mathrm{K}^{+}$e $\mathrm{Ca}^{++}$para o neurônio e despolarização rápida da membrana neuronal durante período de tempo curto. Após algumas centenas de milissegundos, ocorre ativação dos receptores N-metilD-aspartato através de aminoácidos e modulados pela sP e proporcionam influxo de $\mathrm{Ca}^{++}$e de $\mathrm{Na}^{+}$e efluxo de $\mathrm{K}^{+}$. O glutamato atua em receptores metabotrópicos e ativa o aminociclopentano-1,3-de carboxilato, acarretando ativação da fosforilase-C que promove a formação de trifosfato de inositol ou $\mathrm{TPI}_{3}$ e diacil-glicerol ou DAG) e fosforilação das membranas neuronais que se tornam hiperexcitáveis. O DAG estimula a translocação da proteína cinase (PCC) para as membranas celulares. O $\mathrm{TPI}_{3}$ libera $\mathrm{Ca}^{++}$das reservas intracelulares (microssomais) e acarreta formação de ácido araquidônico, substrato da ciclooxigenase COX na produção das PGs. As PGs, por seu turno, aumentam a excitabilidade neuronal, , facilitam a liberação de neurotransmissores excitatórios e reduzem a inibição bulbo-espinal pré-sináptica. A sP também ativa os canais de $\mathrm{Ca}^{++}$dependentes de voltagem, aumentando a penetração de $\mathrm{Ca}^{++}$no interior do neurônio. Os íons $\mathrm{Ca}^{++}$extracelulares somados aos íons $\mathrm{Ca}^{++}$liberados no citoplasma pelas reservas intracelulares atuam como segundos-mensageiros. A ativação de fosfolipase $A_{2} e$ de PCC ligada à membrana dos neurônios nas lâminas superficiais do CMPE gera o fenômeno da despolarização lenta que mantém o wind up, ou seja, aumento da atividade neuronal decorrente da estimulação das fibras C. Graças ao wind-up, há prolongamento da dor após aplicação de estímulos nociceptivos em casos de neuropatias e estímulos de baixo limiar (ativados por fibras A- $\beta$ ) acessam os sistemas centrais de processamento sensitivo ativados normalmente por aferentes C. Protooncogens imediatos como o c-fos, o Krox-24, jun D, o c-jun, jun-B, o fos-B, o MGS-1/A, o MGF-1 e o SRF são expressados em várias estruturas do SNC envolvidas no processo nociceptivo, incluindo a medula espinal, a substância periqüedutal mesencefálica, o núcleos parabraquiais e o tálamo, mecanismo que envolve a PCC. Esses proto-oncogens transcrevem o RNA mensageiro liberado no citoplasma dos neurônios que regula outros genes envolvidos na geração dos canais de membrana, fatores de crescimento, enzimas, canais iônicos e receptores de membrana ${ }^{9}$.

A transferência das informações nociceptivas da medula espinal para estruturas encefálicas é realizada mediante os tratos espinotalâmico, espinorreticular, espinomesencefálico, espinocervical, pós-sináptico do funículo posterior, espinopontoamigdaliano e intracornual ${ }^{10}$. A maioria dos que situam-se nos quadrantes anteriores da medula espinal oposta a entrada de raiz que lhe origina aferência. As fibras de trato espinotalâmico que cruzam a linha mediana e, via quadrante anterolateral oposto da medula espinal, projetam-se nos núcleos do complexo 
ventrobasal, núcleo centrolateral e núcleos intralaminares do tálamo; bulbo, ponte e mesencéfalo, incluindo o núcleo gigantocelular, paragigantocelular e substância cinzenta periaqüedutal mesencencefálica ${ }^{11}$; relacionamse aos aspectos discriminativos e a supressão da dor. $\mathrm{O}$ trato espinorreticular compõem-se de fibras homo e contralaterais que se projetam no núcleo gigantocelular e no tegmento pontino lateral e seus colaterais, no núcleo subcerúleo ventral e dorsal ${ }^{12}$ da formação reticular, promovem a transferência da informação para os núcleos intralaminares do tálamo, tálamo ventral e hipotálamo ${ }^{13}$; relacionando-se às anormalidades neurovegetativas, automáticas, neuroendócrinas, neuroimunitárias, psíquicas e às modificações do sono, do apetite e vida da relação. As fibras do trato espinomesencefálico, cruzam a linha média e projetam-se na formação reticular mesencefálica, incluindo o subnúcelo lateral da PAM e teto mesencefálico; relacionando-se aos aspectos psíquicos e à supressão da dor. As fibras do trato espinopontoamigdaliano e projetam-se contralateralmente via funículo na região parabraquial da ponte, de onde neurônios dirigem-se para o coneurovegetativas e comportamentais de medo, vocalização, dilatação pupilar, reações cárdio-respiratórias, congelamento, etc..., bem como, a memória da dor ${ }^{14}$. As fibras do trato espinocervical originam-se e projetamse unilateralmente no núcleo cervical lateral onde fazem sinapses com neurônios que originam fibras que cruzam a linha média e projetam-se no complexo ventrobasal do tálamo, formação reticular do tronco encefálico e diencéfalo ${ }^{15}$. O trato pós-sináptico do funículo posterior projeta-se nos núcleos gracial e cumeforme ipsilaterais e ralacionam-se a dor visceral ${ }^{16}$.

Do núcleo gigantocelular do troncoencefálico originam-se fibras que se projetam no núcleo centromediano e parafascicular do tálamo ${ }^{17}$. A área pontina parabraquial origina fibras que se projetam na amígdala e no tálamo que participam dos aspectos emocionais relacionados à dor ${ }^{18}$. Tratos de fibras oriundas da região bulbar rostral ventromedial facilitam o processamento das informações nociceptivas no CPME.

Neurônios do complexo ventrobasal do tálamo, projetam-se no córtex orbitário ${ }^{11}$ nos córtices sensitivos SI e SII ${ }^{19}$, neurônios dos núcleos centromediano, parafascicular e intralaminares, projetam-se na estriada e córtex pré-motor e estão relacionados às reações motoras envolvidas no mecanismo de defesa aos estímulos nociceptivos. Há conexões entre o núcleo centromediano, grupamento nuclear posterior do tálamo e o estriado. Há projeções do núcleo caudado no córtex fronto-orbitário, região basomedial da amígdala e áreas de associação dos córteces frontal, occipital e temporal20.

As estruturas que compõem o sistema límbico recebem aferências do núcleo ventral anterior, formação reticular do tronco encefálico e núcleos posteriores do tálamo. O hipotálamo recebe aferências da formação reticular mesencefálica, núcleo ventral anterior do tálamo e córtex frontal.
Poucos neurônios da área sensitiva principal reagem à estimulação nociva ${ }^{17}$. Entretanto, na região posterior da área SIl existem neurônios multimodais que reagem à estimulação nociceptiva que apresentam grandes campos receptivos e são ativados por estímulos bilaterais. $\mathrm{Na}$ área Msl há neurônios que reagem a estímulos somáticos menos específicos. Existem conexões recíprocas entre as áreas sensitivas primárias e secundárias homo e contralaterais e entre estas, e o córtex motor primário, córtex parietal e estruturas do sistema límbico. Conexões dos lobos frontal e temporal exercem atividade facilitatória ou inibitória nos neurônios da PAM e bulbo rostral ventro-medial. Há projeções oriundas do córtex sensitivo primário para o complexo ventrobasal, grupamento nuclear posterior, núcleo parafascicular e, talvez, centromediano do tálamo, com atividade excitatória e inibitória. O córtex sensitivo secundário projeta-se nos núcleos do complexo ventrobasal do tálamo, grupamento nuclear posterior e centromediano. A área motora primária projeta-se nos núcleos talâmicos específicos e inespecíficos. Há projeções oriundas do córtex cerebral sensitivo e motor, córtex orbitário e giro temporal superior exercendo atividade excitatória ou inibitória na formação reticular do tronco encefálico e do córtex sensitivo primário e motor principal nos cornos anterior e posterior da medula espinal e, projeções do córtex orbitário nas lâminas profundas do CPME. Há também projeções oriundas no córteces parietal, occipital e temporal nos núcleos do funículo posterior ${ }^{17}$. A tomografia por emissão de positrons revela aumento do fluxo sangüíneo na região anterior do córtex do cíngulo, nos córtices somatossensitivo primário e secundário, no tálamo contralateral, ínsula, córtex pré-frontal, núcleo lentiforme e no cerebelo após a aplicação de estímulos dolorosos ${ }^{21}$.

Na formação reticular do tronco encefálico estão situados nos núcleos mais importantes para a supressão da dor na medula espinal e no encéfalo ${ }^{22}$.

Vários neurotransmissores proporcionam supressão da dor: leucina e metionina-encefalina presentes nos neurônios e em fibras nervosas da amígdala, tálamo, PAM, núcleos magno e dorsal da rafe, estriato, ponte, bulbo e medula espinal; $\beta$-endorfina nos neurônios da região anterior e intermediária da hipófise e em fibras que, do núcleo arqueado, projetam-se no septo, tálamo, mesencéfalo e PAM; dinorfina na substância negra, sistema límbico, CPME e PAM; néo-endorfina em várias regiões do SNC ${ }^{23}$; 5-HT no núcleo magno da rafe; e Nadr nos neurônios do núcleo do loco cerulleus ${ }^{24}$; neurotensina, glutamato e aspartato na formação reticular bulbar ventromedial, núcleos magno da rafe e reticular gigantocelular -; GABA na PAM e no CPME25-; neurotensina no hipotálamo; dopamina; na substância negra e hipotálamo, calcitonina $^{26}$, adenosina e análogos ${ }^{27}$, somatostatina ${ }^{28}$, vasopressina ${ }^{29}$, glicina ${ }^{28}$ acetilcolina ${ }^{30}$; e neurotensina no CPME; histamina ${ }^{31}$; neurotransmissores canabinóides; etc. Os núcleos serotoninérgicos dorsais da rafe, sob a influência de vias encefalinérgicas, modulam a atividade do acumbente, amígdala e habênula. Há fibras oriundas 
nos núcleos bulbares ventromediais que utilizam 5-HT, Nadr e sP, e que via quadrante dorsolateral da medula espinal projetam-se e suprimindo a atividade nociceptiva nas lâminas superficiais do $\mathrm{CPME}^{26}$. Pouco se conhece a respeito dos mecanismos da modulação da dor no telencéfalo; colaterais do trato corticoespinal oriundos do córtex motor e da área sensitiva primária e secundária exercem atividade inibitória nos neurônios do CPME. O sistema supressor da dor é ativado pela estimulação discriminativa, táctil, térmica e nociceptiva discriminativa e atenua a dor ${ }^{32}$. A duração da dor e o estresse relacionamse à ativação dos sistemas moduladores. A modificação dos paradigmas comportamentais altera a atividade dos neurônios do $\mathrm{CPME}^{15}$. Muito freqüentemente, os indivíduos não percebem imediatamente a dor gerada por traumatismos ${ }^{33}$, enquanto que, em outras situações, o estímulo é percebido com intensidade exagerada ${ }^{34}$. Mecanismos de controle da nocicepção parecem atuar rapidamente, mesmo antes que haja percepção do estímulo ${ }^{35}$. Os neurônios da PAM e da formação reticular bulbar ventromedial são ativados por estímulos nocivos e pelo despertar, sugerindo que a atenção e o alerta estejam envolvidos na sua atividade ${ }^{32}$. Quando a dor torna-se crônica, o comportamento do indivíduo modifica-se e há alterações na fisiologia de vários órgãos ${ }^{36}$.

Enquanto a dor por nocicepção implica em atuação, sensibilização, desinibição neuronal (devida à apoptose dos neurônios supressores) e hipoatividade do sistema supressor, a dor neuropática deve-se à sensibilização neuronal pelas moléculas produzidas durante a degradação de estruturas do SNP ou SNP lesadas e pela atividade neuronal ectópica nos locais de regeneração neuronal e à desinibição neuronal decorrente da hipoatividade do sistema supressor desaferentado ${ }^{37-40}$. Parece haver diferença genética entre os indivíduos, determinando maior ou menor excitabilidade dos receptores e ocorrência de maior ou menor freqüência de dor ${ }^{41}$.

A intensidade da dor e a expressão do sofrimento variam de indivíduo para indivíduo e nas diferentes espécies de animais. Numerosos fatores individuais e ambientais, incluindo aspectos raciais, sociais, culturais, religiosos, filosóficos, experiências pregressas e estado mental dos indivíduos podem exercer efeito amplificador ou atenuador da expressão nociceptiva. O estresse, o medo, a ansiedade e a duração da dor interferem na ativação do sistema opióide envolvido na modulação da analgesia ${ }^{42}$. As endorfinas e outros neuromodulares da nocicepção são liberados quando a dor é intensa ou quando há estresse ${ }^{43}$. A depressão e a ansiedade interagem na percepção da dor via mecanismos inibitórios e facilitatórios ${ }^{44}$. Unidades noradrenérgicas e serotoninérgicas estão envolvidas no mecanismo da ansiedade e da depressão, condições habitualmente associadas à dor crônica. Da interação entre as unidades excitatórias e inibitórias, do estado funcional das estruturas nervosas do alerta, dae atenção, da condição emocional, dos traços constitucionais, experiências pregressas e presentes, da ocorrência de anormalidades orgânicas ou funcionais, e das condições ambientais, a informação nociceptiva pode ou não ser transferida para centros nervosos que participam da percepção ou das reações reflexas frente à dor. Em muitos doentes, particularmente naqueles com dor crônica, desenvolvem-se sofrimento, ganhos secundários e comportamentos dolorosos. O estresse psicológico, por exemplo, torna a dor mais intensa ou menos tolerável. Sofrimento é a resposta emocional negativa a dor.

\section{Dor e depressão}

A dor, como outras sensações, exerce função de adaptação. Enquanto a dor aguda atua como instrumento de alerta, indicando que algo está errado com os meios exterior ou interior ao indivíduo, a dor crônica decorre de estímulos contínuos ou recorrentes, mas pode ocorrer mesmo na ausência deles e causa sofrimento e incapacidade. Sua função biológica é menos definida; talvez exerça funções relacionadas à memória e proteção da região acometida ${ }^{45}$. Poucos são os dados existentes a respeito dos mecanismos de supressão de dor crônica e das modificações do padrão da atividade dos neurotransmissores nessa eventualidade. É bem provável que os mecanismos envolvidos na manifestação da dor crônica sejam diferentes daqueles observados em casos de dor aguda. Em animais submetidos a regime de dor crônica há aumento da concentração de metencefalina e de dinorfina no CPME e de dinorfina no tálamo ${ }^{23}$ e redução do limiar aos estímulos mecânicos. Esse último fenômeno acentua-se quando há bloqueio dos receptores $\kappa$. Ocorre também redução do número de receptores $\kappa$ e aumento dos receptores $\mu$, o que indica elevação da atividade dinorfinérgica ${ }^{23}$.

Esses, dentre outros mecanismos, podem ser responsáveis pela modificação do padrão funcional nos neurônios convergentes na medula espinal ${ }^{46}$, e no complexo ventrobasal e núcleo intralaminar do tálamo nessas eventualidades ${ }^{32}$.

\section{Dor e anormalidades psíquicas}

Várias são as anormalidades psíquicas relacionadas à dor crônica (Quadro 1).

Segundo Wortz ${ }^{48}$, observou que queixas clínicas compunham integralmente as síndromes depressivas, $30 \%$ a $100 \%$ dos doentes com depressão, especialmente quando acompanhada de ansiedade, apresentam queixas dolorosas. Doentes deprimidos freqüentemente queixam-se de dor crônica, muitas vezes em vários segmentos do corpo na ausência de lesões ou de justificativas para tal e geralmente consultam profissionais das mais variadas especialidades sem, no entanto, obterem melhora satisfatória ${ }^{49}$. Os transtornos depressivos são, após a insônia, a segunda anormalidade mais freqüentes em pacientes com dor. 
A depressão é mais comum nos portadores de dor crônica, quando comparados aos controles sadios ${ }^{50}$. Doentes com dor crônica geralmente apresentam raiva, hostilidade, comprometimento cognitivo, ansiedade, depressão, transtornos mistos ansiosos e depressivos. Sofrem muita influência de estressores psicossociais e socioeconômicos, depressões recorrentes e se beneficiam com o tratamento com antidepressivos ${ }^{51}$. Queixas dolorosas podem desencadear medo, dependência ou mesmo comportamentos para obtenção de benefícios que surgem com o adoecimento ${ }^{52}$. Em alguns casos, o sofrimento relacionado à dor domina o quadro clínico e a síndrome depressiva associada só é reconhecida meses ou, muitas vezes, anos após ${ }^{48}$. Sintomas de depressão maior ocorrem entre $1,5 \%$ a $57 \%$ dos pacientes com dor crônica e a distimia, em 4,3\% a $48,6 \%{ }^{48,53}$. Baseando-se em entrevistas com médicos, Lindsay e Wyckoff ${ }^{54}$ concluíram que, a depressão manifesta-se em $87 \%$ dos doentes com dor crônica; a população analisada nesses estudos geralmente contempla indivíduos atendidos em instituições ou clínicas especializadas onde os doentes geralmente são mais comprometidos do que aqueles atendidos nas unidades de cuidados primários. Ocorrem transtornos depressivos em cerca de 50\% dos doentes com dor, incluindo a cefaléia, a dor facial, a cervicalgia, a lombalgia, as dores torácica, abdominal e pélvica, e dor nas extremidade ${ }^{55}$ e em $22 \%$ a $78 \%$ nos doentes com dor crônica que necessitam tratamento especializado ${ }^{56}$. Kramlinger et al. ${ }^{57}$ observaram que eram deprimidos $25 \%$ dos doentes submetidos a programa de manejo de dor na Clínica Mayo e, provavelmente deprimidos 39\%. Maruta et al. ${ }^{58}$, observaram que $34 \%$ dos indivíduos internados apresentavam depressão, 29\% provavelmente a apresentavam e 36\% não eram deprimidos. Ocorrem sintomas depressivos intensos em $25 \%$ dos pacientes portadores de neoplasias freqüência esta que se eleva para 70\%, naqueles em estágio avançado 5,56,59-61 maior expressa-se com sinais e sintomas que superam a reação "normal" do indivíduo, frente a situações de perda ou luto e comprometem significativamente o relacionamento familiar, o desempenho profissional, o convívio social e inclusive o prognóstico de várias doenças, podendo ainda ter como conseqüência maior, o suicídio ${ }^{63}$. A ideação suicida, a sensação de fracasso, a sensação de culpa, o isolamento social, a indecisão e a perda de satisfação determinam a intensidade da depressão ${ }^{64}$. A depressão agrava a funcionalidade social e ocupacional dos pacientes com dor ${ }^{65}$. Sintomas depressivos influenciam a vivência e o controle da sintomatologia álgica, o resultado e a adesão do tratamento, e aumentando a utilização de serviços de saúde ${ }^{66)}$. Doentes deprimidos e com dor crônica são menos ativos que os não deprimidos ${ }^{67}$. A depressão somada à dor agrava as alterações funcionais. Doentes com neoplasia maligna e dor apresentam mais neurotização, mais depressão e executam menos atividades físicas, quando comparados aos sem dor ${ }^{60,68}$. A dor incontrolada é fator de suicídio em doentes com câncer. Doença avançada com mau prognóstico, depressão, delirium, perda de controle, abandono, psicopatologia pré-existente, história de tentativa de suicídio, antecedentes familiares de suicídio, fadiga e exaustão relacionam-se à ocorrência de dor ${ }^{59}$. Cerca de $20 \%$ de doentes terminais, verbaliza ideação suicida e alguns suicidam-se ${ }^{61}$. Há correlação positiva, entre a intensidade da dor e a "crença" de que a dor significa agravamento ou progressão da doença e maior uso de analgésicos com anormalidades do humor em doentes com câncer ${ }^{69,70}$.

Estas considerações, confirmam a hipótese de que a depressão pode evoluir com dor e esta com depressão, constituindo assim um ciclo vicioso, dor-depressão-dor. Entretanto, a relação causal entre dor e depressão é controversa. É freqüentemente difícil afirmar quem surgiu antes, a dor ou a disfunção psicológica ou comportamental ${ }^{56,60,71,72}$. Observou-se que em aproximadamente 50\% dos doentes com dor e depressão, tinham desenvolvido

Quadro 1. Prevalência dos diagnósticos psiquiátrico segundo o DSM-III-R em doentes com dor crônica (47)

\begin{tabular}{|c|c|c|c|c|}
\hline & Dor crônica $(n=382)$ & População geraL $(n=5495)$ & & \\
\hline Diagnóstico & & & $\mathrm{Chi}^{2}$ & $\mathbf{P}$ \\
\hline Qualquer transtorno do humor & $83(21,7)$ & $551(10,0)$ & 31,13 & $<0,0001$ \\
\hline Depressão & $77(20,2)$ & $510(9,3)$ & 26,53 & $<0,0001$ \\
\hline Distimia & $20(5,2)$ & $128(2,3)$ & 5,48 & $<0,01$ \\
\hline Qualquer transtorno de ansiedade & $134(35,1)$ & $992(18,1)$ & 21,54 & $<0,0001$ \\
\hline Transtorno de ansiedade generalizado & $28(7,3)$ & $144(2,6)$ & 9,1 & $<0,0005$ \\
\hline Transtorno do pânico com agorafobia & $25(6,5)$ & $103(1,9)$ & 7,84 & $<0,01$ \\
\hline Fobia simples & $60(15,7)$ & $103(1,9)$ & 7,84 & $<0,01$ \\
\hline Fobia social & $45(11,8)$ & $428(7,8)$ & 5,91 & $<0,05$ \\
\hline Agorafobia com ou sem pânico & $32(8,4)$ & $182(3,3)$ & 6,52 & $<0,05$ \\
\hline Transtorno de estresse pós-traumático & $41(10,7)$ & $182(3,3)$ & 16,29 & $<0,001$ \\
\hline
\end{tabular}

A depressão é condição anormal e difere qualitativamente da tristeza e da desesperança. Humor depressivo, tristeza ou desânimo devem ser interpretados como reações normais à situações desagradáveis, frustrações ou perdas. Quando temporárias e de pequena magnitude não interferem marcadamente no desempenho e não são associadas a constelação dos sintomas ou condições clínicas que acompanham a depressão62. A depressão ambos sintomas concomitantemente. Fishbain et al. ${ }^{73}$ concluíram que em nove de treze estudos a depressão não precedeu a ocorrência de dor crônica ${ }^{54}$, enquanto que, em um, os resultados foram mistos. Observaram que 38\% a 46\% dos doentes passaram a apresentar depressão após a instalação da dor e, que em 0\% a 12\%, a dor instalou-se após ocorrência da depressão. Portanto, na maioria dos casos, não há fatores precedentes, enquanto em outros, 
a dor é utilizada para focalizar aberrações durante eventos difíceis; raramente ambas as duas condições coincidem. Leino e Magni ${ }^{74}$ observaram que sintomas depressivos predisseram a evolução de disfunções músculo-esqueléticas. Von Korff et al. ${ }^{75}$, acompanhando pacientes por período de 3 anos, observaram que os pacientes deprimidos desenvolveram cefaléia intensa e dor torácica em frequência maior do que os controles. É possível que, nessas condições, a dor possa ser sintoma de síndrome depressiva ou ambas possam resultar de processo psicobiológico comum. Doentes com dor crônica intensa, apresentam anormalidades psicopatológicas distintas em relação àqueles que apresentam depressão determinada genética ou metabolicamente. Apresentam também irritabilidade, disforia, redução do interesse e da capacidade de adaptação. Pacientes com depressão intensa, apresentam anedonia, despertar precoce, indecisões, tendências suicidas, desespero existencial e alguns traços psicóticos. Desse modo, a ocorrência de dor somática prolongada associada ao padrão de síndrome algiogênica psicoorgânica suporta a suposição clínica de que a dor é a causa e, a depressão, o resultado ${ }^{48}$.

Deficiência de neurotransmissores, alterações nos receptores, transtorno dos ritmos biológicos, anormalidades neuroendócrinas, imunológicas e fatores genéticos são justificativas para a ocorrência da depressão em doentes com dor crônica.

Muitos deprimidos, apresentam redução do limiar para a percepção de dor ${ }^{76}$. A ansiedade freqüentemente associa-se à depressão; o estado de ansiedade aumenta a tensão muscular que, por sua vez, é causa da síndrome dolorosa miofascial ${ }^{77,78}$. Dor e depressão envolvem mecanismos bioquímicos similares que podem resultar em menor disponibilidade de neurotransmissores no SNC, incluindo o aminas como a 5-HT, a (Nadr) e a dopamina ${ }^{79}$; o ciclo vicioso dor-depressão-dor envolveria a hipoatividade de 5-HT e de Nadr e comprometeria a atividade do sistema inibidor. Parece haver relação entre a menor atividade dos neurotransmissores opióides endógenos e depressão em doentes propensos a apresentar dor ${ }^{56}$. Alguns trabalhos, entretanto, demonstraram que doentes com dor e depressão apresentam elevadas concentrações de $\beta$-endorfina no plasma e no líquido cefalorraquidiano ${ }^{80,81}$. Mecanismos noradrenérgicos exercem papel fundamental na modulação da dor, pois a Nadr produzida no núcleo do loco cerúleo e liberada na medula espinal reduz o limiar da dor ${ }^{82,83}$. É possível que ocorra defeito na regulação noradrenérgica em doentes deprimidos, do que resultaria comprometimento da atividade noradrenérgica basal de Nadr em casos de dor crônica ${ }^{56}$. Animais mantidos prolongadamente sob estímulos nocivos parecem desistir de enfrentar estas situações; é possível que as alterações serotoninérgicas e noradrenérgicas criem a síndrome da desassistência aprendida ${ }^{84}$. Doentes com dor apresentam sensação de desassistência, não mais queixam-se quando não controlam os eventos e imaginam que nada é capaz de ajudá-los. Segundo a teoria psicobiológica da desassistência aprendida, os esforços com objetivo de dar aos doentes a sensação de controle da dor e o uso de antidepressivos (ADs) seriam eficazes no tratamento da dor crônica em doentes deprimidos. Muitos deles apresentam redução da atividade serotoninérgica ${ }^{85}$. A hipoatividade serotoninérgica aumenta a sensibilidade à dor 82,83 ; os $\mathrm{ADs}$ com atividade serotoninérgica são eficazes no tratamento da dor. Em algumas doentes, o controle da depressão pode também resultar em melhora do desempenho funcional além da dor; os ADs ocasionam e aumentam a disponibilidade de 5-HT e Nadr na fenda sináptica e melhoram não apenas a depressão, como também, a dor. A atividade serotoninérgica parece estar mais relacionada ao controle da dor crônica do que da aguda. A fenfluranina, liberador específico de 5-HT, é eficaz em algumas condições de dor crônica mas não de dor aguda. Por outro lado, a dextroanfetamina que libera Nadr e dopamina reduz tanto a dor aguda como a crônica, mas não prediz o efeito dos Ads ${ }^{86}$. Muitos ADs apresentam outras ações além da serotoninérgica e noradrenérgica ${ }^{87}$ e aumentam um ou vários neurotransmissores na fenda sináptica, via bloqueio na recaptação neuronal, ativação de receptores ou inibição de enzimas específicas. Entretanto, os elevados níveis de 5-HT não refletem atividade do receptor. As teorias biológicas, entretanto, não justificam o alentecimento para a ocorrência da melhora da depressão com o emprego de ADs, o que é observado geralmente, após a segunda semana de tratamento. Isto significa que para a resolução dos sintomas de depressão pode haver necessidade de modificações adaptativas na neurotransmissão assim como, do número e subsensibilização dos receptores. Não foram, entretanto, observadas modificações na concentração do ácido 5-hidroxi-indolacético nos doentes com dor psicogênica ou orgânica; os níveis desse metabólito são mais elevados em doentes com dor do que nos sem dor e não são os mesmos em condições de dor aguda ou crônica ${ }^{88}$.

A teoria neuroendocrinológica fundamenta-se no fato de que muitos doentes com depressão não suprimem a síntese de cortisol com a utilização de dexametasona e muitos apresentam também anormalidades na liberação do $\mathrm{TSH}^{89}$. A teoria imunológica baseia-se no fato de os doentes deprimidos apresentarem deficiência imunológica que os predispõem a outras enfermidades. O transtorno dos ritmos biológicos justificaria a normalização do ciclo sono-virgília e o fato da fototerapia ser eficaz no tratamento da depressão sazonal.

A teoria genética fundamenta-se no fato de a depressão ser documentada em familiares e em gêmeos ${ }^{89}$ de doentes $\mathrm{com}$ dor $^{90}$. Defeitos da membrana neural determinados geneticamente induziriam desregulação da interação entre neurotransmissor e receptor e causaram impacto nos sistemas de segundos mensageiros dos circuitos neuronais, resultando em anormalidade dos ritmos biológicos e da 
função neuroendócrina. É o que ocorreria em casos de personalidade propensa à dor ${ }^{91}$. Devida à susceptibilidade genética, episódios prévios de depressão predispõem alguns indivíduos a episódios depressivos após a instalação da dor ${ }^{6}$. Doentes com dor e depressão parecem apresentar freqüência maior de episódios depressivos prévios.

Segundo as teorias psicológicas, a dor é a causa da depressão92; instalar-se-ia um ciclo vicioso de modo que a depressão tornaria a dor menos tolerável. Segundo Wörtz ${ }^{48}$ interpretava a dor como punição pelo desejo proibido. A dor crônica criaria processo protraído de tristeza; a depressão manifestar-se-ia quando o impacto da dor crônica tornar-se aparente. A depressão clinica poderia resultar da falha da resolução da tristeza ${ }^{93}$; a depressão resolver-se-ia quando o impacto da dor crônica torna-se aparente. A depressão clínica poderia resultar da falha da resolução da tristeza ${ }^{93}$ a depressão resolver-se-ia quando ocorresse plena aceitação da dor. Engle $^{91}$ observou relação entre negligência e abuso na infância em casos de personalidade propensa à dor; nos indivíduos com dor e depressão existe agressão autoinfligida e a dor atua como instrumento de comunicação; a hospitalização de adultos seria fator de risco tanto para a doença depressiva como para a ocorrência de dor incontrolável. Rudy et al. ${ }^{94}$ observaram que a ocorrência de dor não é suficiente para o desenvolvimento subseqüente de dor; postularam que a redução das atividades instrumentais em paralelo com a redução de alguns traços de personalidade seriam as correlações possíveis entre dor e depressão; detectaram alteração na percepção da interferência da vida e redução do auto-controle em 100 doentes encaminhados para tratamento da dor. Em alguns doentes, a dor crônica compromete os eventos agradáveis da vida e induz depressão conjuntamente com o desenvolvimento de atitudes prévias negativas ou disfuncionantes que induzem a vivência da vida sob prisma negativo.

A dor crônica é variante de anormalidade do humor com traços clínicos e psicológicos característicos. A dor crônica pode assim ser considerada "depressão mascarada". Causas evidentes para a persistência de dor podem não ser identificadas na maioria dos doentes. Os doentes com predisposição para dor apresentariam sintomáticos, dor contínua de causa obscura, preocupações hipocondríacas e desejo de cirurgia. O indivíduo estável apresentaria caracteristicamente negação de conflitos, ergomania, atividade intensa, alexitimia, etc. Segundo Herr et al ${ }^{95}$ dor e depressão coexistem mas a dor crônica é insuficiente para a determinação de quadros depressivos. Segundo o modelo cognitivo-comportamental, a redução das atividades, os sentimentos de perda de prestígio social e de controle da situação que freqüentemente ocorrem em condições álgicas, ocasionam depressão. O indivíduo deprimido, centrado em si mesmo, afastado do convívio social e das atividades laborais é mais susceptível a perceber a dor ${ }^{56,68,71}$. Perdas ou condições desfavoráveis de maior magnitude na relação com outras pessoas freqüentemente precipitam a ocorrência de depressão92. Estudos preliminares sugerem que doentes com lombalgia aguda são mais propensos a apresentar dor crônica quando estão insatisfeitos consigo mesmos ou com suas vidas ou apresentam problemas conjugais ou conflitos com parceiros no trabalho ${ }^{96}$. Não foi esclarecido o tanto quanto ganhos secundários, incluindo o não comparecimento ao trabalho ou às atividades escolares, a evitação de eventos ou os contatos com pessoas inconvenientes mediam o desenvolvimento de dor crônica. Os conflitos interpessoais podem precipitar a depressão, do mesmo modo que contribuem para a perpetuação da dor. Estes mecanismos criariam ciclo negativo que induz o doente a afastar-se de situações sociais e o torna hostil para com outras pessoas; o suporte social modifica-se e o doente focaliza-se mais em sua dor.

Doentes com depressão apresentam anergia, falta de iniciativa, inatividade, fadiga, anedonia, insônia e desespero. Geralmente apresentam história familiar e pessoal de depressão, alcoolismo, abuso sexual e de familiares incapacitados ou com dor crônica. A associação dor e depressão não implica que a depressão seja causa de dor; a depressão usualmente é episódica e dura menos de um ano enquanto que em doentes com dor crônica a depressão que dura prolongamento. Muitos doentes não apresentam predisposição para dor e, quando o fazem, não apresentam evidências de depressão. Esses achados estão de acordo com as teorias das aminas neurotransmissoras.

\section{Fenômenos associados à depressão no doente com dor crônica}

A ansiedade e a depressão ocorrem em doentes com dor e podem estar correlacionadas à dor crônica; 35\% da população com dor crônica contempla o critério de diagnóstico de ansiedade. A ansiedade, independentede outros fatores, pode aumentar a tensão muscular que agravam a condição dolorosa inicial e é causa de cefaléia, dor torácica, epigastralgia, etc. A dor decorrente da tensão aumenta a ansiedade e perpetua o ciclo dor-tensão-dor 52 .

Em doentes com dor crônica, depressão, ansiedade ou medo, há superposição da atividades encefálica.

A síndrome da fadiga crônica, transtorno freqüentemente associado à dor, é significativamente associada à depressão ${ }^{97}$. Fadiga e alterações do sono são os dois mais indicadores comuns de depressão em cuidados primários ${ }^{98}$. Os doentes com dor crônica tipicamente permanecem mais tempo na cama ou em repouso, embora também relatem que seu sono não é normal e reparador.

\section{DIAGNÓSTICO}

A avaliação adequada do doente com dor deve incluir a análise dos aspectos psicológicos da dor, seus efeitos no comportamento e na estabilidade emocional bem como a 
investigação das anormalidades psíquicas s comumente a eles associados. A avaliação é um desafio pois muitos doentes não têm consciência da importâncias das questões psíquicas ou tornam-se relutante em acessá-las aspectos mentais ou é relutante em acessá-los e socialmente, é mais aceitável procurar auxílio de clínico geral do que de cuidados psiquiátricos ${ }^{99}$. Portanto, como componente integrante desta investigação, o clínico deve, incluir questões referentes ao humor, sono, preocupação com sintomas somáticos, diminuição da atividade e da libido, fadiga, ansiedade, uso inadequado de medicamentos ou drogas, ideação suicida e alterações comportamentais, sociais e ocupacionais e questões financeiras. $\mathrm{O}$ tratamento da dor crônica só pode ser planejado com eficácia após a determinação da etiologia primariamente orgânica ou não somática e implica na realização do exame clínico e de história clínica e psiquiátrica detalhadas.

\section{TRATAMENTO}

O tratamento da dor deve basear-se na etiologia e fisiopatologia da dor e suas repercussões ${ }^{100}$; deve envolver a eliminação do fator causal, uso de fármacos analgésicos e adjuvantes e medidas não farmacológicas incluíndo os recursos de medicina física e de reabilitação em conjunto com os procedimentos psicoterápicos e com técnicas e materiais educativos ${ }^{101,102}$. Em situações excepcionais, procedimentos anestésicos e neurocirúrgicos podem ser valiosos no alívio de determinadas algias resistentes. O conjunto destas estratégias terapêuticas oferecidas por equipes multiprofissionais e interdisciplinares, visa a reduzir a dor e o uso de medicamentos, reintegrar funcionalmente o doente, melhorar o enfrentamento, e do sistema de saúde, melhorar a qualidade de vida e otimizar a relação custo-benefício das intervenções.

Em casos de dor aguda, as intervenções visam à eliminação do desconforto e recorrem fundamentalmente à remoção das causas, à farmacoterapia analgésica e aos procedimentos simples de medicina física e de medicina comportamental ${ }^{103}$. Em casos de dor crônica, o tratamento fundamenta-se no emprego de medidas sintomáticas, especialmente no uso de medicamentos adjuvantes, medicina física e reabilitação, psicoterapia e intervenções de reintegração social. A prescrição de medicamentos é, geralmente, a primeira atitude analgésica adotada para ambas as condições. Os bloqueios anestésicos são úteis para o tratamento da dor aguda, síndrome complexa de dor regional e para a realização de procedimentos cirúrgicos e manipulações de estruturas traumatizadas ${ }^{104}$. As medidas fisiátricas visam ao alívio da dor, à melhora do desempenho físico, à prevenção, ao tratamento, à minimização das anormalidades estruturais ou funcionais primárias e das repercussões orgânicas da dor e do imobilismo e à prevenção da recorrência da sintomatologia. Os procedimentos psicocomportamentais visam à eliminação dos comportamentos doentios e de evitação, à melhor aceitação da doença, à melhora da funcionalidade e à indução do uso de estratégias de enfrentamento mais adequadas $^{105}$. A equipe de medicina social visa à reintegração social e profissional dos doentes nos seus ambientes originais ou adaptados às suas realidades.

\section{Antidepressivos}

Os ADs são, entre os psicofármacos, os mais utilizados em doentes com dor crônica, deprimidos ou não. A prescrição de ADs por não psiquiatras. Somente 16\% dos deprimidos tratados por clínicos que não recebem tratamento adequado ${ }^{106}$. São eficazes no tratamento de várias situações dolorosas, como cefaléia, dor facial, artralgias, neuropatia diabética, síndrome fibromiálgica, mialgias e dor no doente decorrente do câncer e na profilaxia da cefaléia de tensão e da enxaqueca. Atuam no SNC alterando a sensibilidade dos receptores, a recaptura de $\mathrm{Nadr}$ e 5-HT, no CPME via fascículo rostrocaudal, dorsolateral, inibitório da dor e no SNP inibindo preferencialmente os canais de $\mathrm{Na}^{+}$. A seleção do antidepressivo deve basear-se na natureza da doença e da dor, idade e estado de saúde do doente e nos efeitos adversos potenciais do medicamento. Drogas com mais efeito sedativo são geralmente as preferidas já que a insônia é comum em muitos doentes com dor crônica ${ }^{100}$.

Os ADs, como a amitriptilina, a imipramina e a nortriptilina são as mais utilizadas. A dosagem inicial geralmente varia de 25 a 50mg/dia; esta deve ser elevada gradualmente de $25 \mathrm{mg}$ a cada três a quatro dias, após a primeira semana, de acordo com a tolerabilidade. A dosagem deve ser reduzida se ocorrerem efeitos colaterais insuportáveis. O efeito terapêutico geralmente instala-se após cinco a sete dias. O padrão de sono tende a melhorar durante os primeiros três dias e o alívio da dor aumenta durante o primeiro mês. Geralmente não há benefício adicional, quanto à melhora da dor com dosagens superiores a 150mg/dia; nãoé necessário o uso de doses habitualmente utilizadas no tratamento da depressão quando apenas a dor é de razão de intervenção. Os ADs duais como a venlafaxina (18,75 a 150mg/dia) e a duloxetina (60 a 120mg/dia) também apresentam efeito analgésico ${ }^{107,108}$. Os efeitos colaterais dos ADs são potencializados por outras medicações como os opióides ${ }^{100}$.

A eficácia da fluoxetina é controversa ${ }^{109,110}$ - apesar da fraca evidência de poder analgésico em casos de dor músculo-esquelética, incluindo a osteoartrose ${ }^{111}$, síndrome fibromiálgica ${ }^{112}$. A fluvoxamina mostrou-se eficaz como a amitriptilina na profilaxia da enxaqueca segundo um estudo duplamente encoberto ${ }^{113}$. A paroxetina mostrou-se menos eficaz do que a maprotilina (150mg/dia) no tratamento da lombalgia ${ }^{115,116}$.

\section{Centros multidisciplinares}

Os Centros Multidisciplinares de Dor oferecem tratamento para síndromes dolorosas difíceis; sua eficácia é reconhecida. A Comission on Accreditation of Rehabilitation Facilities (1990) estabeleceu que a equipe nuclear de profissionais de saúde deveria contar no mínimo, com três indivíduos, sendo um deles, de psicologia ou psiquiatria. $\mathrm{O}$ acesso a outros especialistas aumenta a abrangência do programa e possibilita a oferta de várias modalidades de tratamento e enfatiza sobremaneira a reabilitação física, o condicionamento para o trabalho, os tratamentos psicológicos, os tratamentos farmacológicos e a educação de doentes e de seus familiares. 
Nos centros multiprofissionais de dor, a avaliação é realizada por vários especialistas que não utilizam critérios diagnósticos de exclusão e não adotam hierarquia relacionada à importância dos diversos diagnósticos decorrentes das várias observações, mas combinam diferentes especialidades sob visão integrada da dor crônica em conjunto com os doentes. Os profissionais envolvidos devem reconhecer que a dor apresenta várias causas, que todos os diagnósticos devem ser considerados reais, compatíveis e coexistentes. Quando o diagnóstico não é realizado, deve-se assumir que a causa do sintoma é incerta e o paciente deve receber tratamentos sintomáticos e orientações para futuras investigações e não ser estigmatizado como apresentando condições falsas mas sim, problemas legítimos associados a sofrimentos e prejuízos compreensíveis ${ }^{106}$. Programas interdisciplinares de manejo da dor oferecem contexto no qual o doente com dor geralmente torna-se capaz de aceitar as intervenções psicológicas ${ }^{100}$.

Existem evidências de que estes programas melhoram significativamente o funcionamento dos pacientes ${ }^{106}$.

\section{CONCLUSÃO}

A dor freqüentemente é associada a problemas psicológicos e sociais, particularmente quando torna-se crônica. A ansiedade e a depressão são correlatas particularmente comuns da dor e devem ser identificadas e tratadas. Dor crônica é comumente associada a indicadores de depressão, incluindo a redução da qualidade do sono, anorexia, inatividade, anergia, comprometimento da capacidade de concentração, anedonia e ideação suicida. A elevada morbidade psiquiátrica associada em doentes com dor crônica constitui elemento freqüentemente complicador dos cuidados dispensados exclusivamente pelo clínico.

O objetivo terapêutico no doente com dor crônica não é a cura; procedimentos analgésicos e cirúrgicos raramente são curativos nestes casos ${ }^{117}$. Os avanços recentes no tratamento da dor crônica incluem o diagnóstico e o tratamento das morbidades psiquiátricas associadas e adoção de atitudes interdisciplinares para oferecer cuidados abrangentes, integrais e integrados ${ }^{106}$. A ocorrência de psicopatologia não deve desviar o médico da consideração para com o diagnóstico e tratamento de problemas dolorosos específicos.

\section{REFERÊNCIAS BIBLIOGRÁFICAS}

1. Teixeira MJ. Dor no Brasil: estado atual e perspectivas. São Paulo: Editora Limay; 1995

2. Merskey H, Albe-Fessard DG, Bonica JJ, Carmon A, Dubner R, Kerr FWL et al. Pain terms: a list with definitions and notes on usage. Recommended by the IASP subcommittee on Taxonomy. Pain 1979; 6: 249-252.

3. Anderson HI, Ejlertsson G, Leden I, Rosenberg C. Chronic pain in a geographically define general population: study of diferences in age, gender graphial class and pain localization. Clin J Pain 1993; 9:174-182.

4. Merskey H, Bogduk N. Classification of chronic pain. 2nd ed. Seattle: IASP Press; 1994.

5. Cassem EH. Depression and anxiety secondary to medical illness. Psychiat Clin North Am 1990;13: 597-611.

6. Salt TE. The possible involvement of excitatory amino acids and NMDA receptors in thalamic pain mechanisms and central pain syndromes. Am Pain Soc J 1992; 1: 52-54.

7. Basbaum A, Bushnell MC. Pain: basic mechanisms. In: Glamberardino MA. Pain 2002 - an Updated Review - International Association for the Study of Pain, Seattle, IASP Press; 2002. p. 3-7.

8. Fessell TM, Dodd F. Function chemistry of primary afferent neurons. In: Wall PD, Melzack R (eds). Textbook of pain. Edinburgh: Churchill Livingstone; 1989. p. 82-99.

9. Teixeira MJ. Anatomia e fisiologia das unidades nociceptivas e supressoras da dor. In: Teixeira MJ, Braum Filho JL, Marquez JO, Lin TY (eds). Dor: contexto Interdisciplinar. Curitiba: Editora Maio; 2003. p.119-46.

10. Denis SG, Melzack R. Pain-signalling systems in the dorsal and ventral spinal cord. Pain 1977; 4: 97-132

11. Ignelzi RJ, Atkinson JH. Pain and its modulation. Neurosurgery 1980; 6: 577-583.

12. Willis WD. The origin and destination of pathways involved in pain transmition. In: Wall PD, Melzack R (eds). Textbook of pain. Edinburgh: Churchill Livingstone; 1989. p. 112-27.

13. Bowsher $D$. Role of the reticular formation in response to noxious stimulation. Pain 1976; 2: 361-378

14. Basbaum A, Bushnell MC. Pain: basic mechanisms. In: Giamberardino MA. Pain 2002 - an Updated Review - International Association for the Study of Pain, Seattle, IASP Press; 2002. p. 3-7.

15. Wall DM. Effect of peripheral nerve injury on receptive fields of cells in the cat spinal cord. J Comp Neurol 1981; 199: 277-291.

16. Brown AG. Cutaneous axons and sensory neurons in the spinal cord. Br Med Bull 1977; 33:109-112.

17. Bowsher D. Termination of the central pain pathway in man: the conscious appreciation of pain. Brain 1957; 80: 606-622

18. Guilbaud G, Besson JM, Oliveras JL, Wyon-Maillard MC. Modification of the firing rate of bulbar reticular units (nucleus gigantocellularis) after intra-arteria injection of bradykinin into the limb. Brain Res 1973; 63:131-140.

19. Tasker RR, Emmers R. Patterns of somesthetic projection in SI and SII of the human thalamus. Confin Neurol 1967; 29:160

20. Craig AD, Wiegand SJ, Price JL. The thalamocortical projections of the nucleus submedius in the cat. J Comp Neurol 1982; 206:28-48.

21. Casey KL, Minoshima S, Berger KL, Koeppe RA, Morrow TJ, Frey KA. Positron emission tomographic analysis of cerebral structures activated by

repetitive noxious heat stimuli. J Neurophysiol 1994; 71:802-807.

22. Cervero F, Iggo A. The substantia gelatinosa of the spinal cord: a critical review. Brain 1980; 103: 717-772

23. Hertz A. Opiates, opioids and their reception in the modulation of pain. Acta Neurochir 1987; 38(Suppl):36-40

24. Yaksh TL, Hammond DL. Peripheral and central substrates involved in the rostral transmission of nociceptive information. Pain 1982; 13:1-85.

25. Willis WD, Kenshalo DR Jr, Leonard RB. The cells of origin of the primate spinothalamic tract. J Comp Neurol 1979; 188:543-574.

26. Yaari Y, Devor M. Phenytoin suppresses spontaneous ectopic discharge in rat sciatic nerve neuromas. Neurosci Lett 1985; 58:117-122.

27. Willis WD, Coggesshall RE. Sensory mechanisms of the spinal cord. New York: Plenum Press; 1978. p. 485.

28. Blumenkopf B. Neurochemistry of the dorsal horn. Appl Neurophysiol 1988; 51:89-103.

29. Berson BS, Berntson GG, Zipf W, Torello MW, Kirk WT. Vasopressin-induced antinociception: an investigation into its physiological and hormonal basis. Endocrinology 1983; 11:337-343

30. Brodie MS, Proudfit HK. Hypoalgesia induced by the local injection of carbachol into the nucleus raphe magnus. Brain Res 1984; 291: 337-342.

31. Hammond DZ, Levy RA, Proudfit HK. Hypoalgesia following microinjection of noradrenergic antagonists in the nucleus raphe magnus. Pain 1980; 9: 85-101.

32. Leavens ME, Hill CS Jr, Cech DA, Weyland JB. Weston JS. Intrathecal and intraventricular morphine for pain in cancer patients: initial study. J Neurosurg 1982; 56:241-245.

33. Melzack R, Wall PD, Ty TC. Acute pain in an emergency clinic: latent of onset and descriptor patterns related to different injuries. Pain 1982; 14: 33-43.

34. Levine JD, Gordon NC, Fields HW.- The mechanisms of placebo analgesia. Lancet 1978; 2:654-657.

35. Melzack R. The Puzzle of pain. Auckland: Penguin Books; 1977

36. Wall PD. Introduction. In: Wall PD, Melzack R, editors. Textbook of pain. Edinburgh: Churchill Livingstone; 1989. p. 1-18

37. Boivie J. Central pain. In: Wall PD, Melzack R (eds). Textbook of pain. New York: Raven Press; 1994. p. 871-902.

38. Hsieh JC, Belfrage M, Stone-elander S. Central representation of chronic ongoing neurophatic pain studied by positron emission tomography. Pain 1995; 17: 22-30.

39. Kawakami M, Weinstein NJ. Associated neurogenic and nonneurogenic pain mediators that probably are activated and responsible for nociceptive input. In: Weinstein JN, Gordon SL (eds). Low back pain. A scientific and clinical overview. Am Acad Orthop Surg. 1995; p. 265-73.

40. Rosenthal AK, Wostmann RL. Diagnosis pathogenesis, and management of reflex simpathetic distrophy syndrome. Compar Ther 1991; 17:46-50.

41. Devor M, Wall PD. Plasticity in the spinal cord sensory map following peripheral nerve injury in rats. J Neurosci 1981; 1: 679-684

42. Broton JG, Rosenfeld JP. Rostral trigeminal projections signal perioral facial pain. Brain Res 1982; 243:395-400

43. Terman GW, Shavit Y, Lewis JW, Cannon JT, Liebeskind JC. Intrinsic mechanisms of pain inhibition: activation by stress. Science 1984; 236:231-235.

44. Meyer RA, Raja SN, Campbell JN. Coupling of action potential activity between unmyelinated fibers in the peripheral nerve of monkey. Science 1985; 227:184-187. 
45. Teixeira MJ. A lesão do trato de Lissauer e do corno posterior da substância cinzenta da medula espinal e a estimulação elétrica do sistema nervoso central para o tratamento da dor por desaferentação [tese]. São Paulo: Faculdade de Medicina, Universidade de São Paulo; 1990.

46. Calvino B, Villanueva L, Bars D. Dorsal horn (convergent) neurons in the intact anaesthetized arthritic rat. I. Segmental excitatory influences. Pain 1987: 28:81-98

47. McWilliams LA, CoxBJ, Enns MW. Mood and anxiety disorders associated with chronic pain: an examination in a nationally representative sample. Pain 2003; 106:127-133.

48. Wörtz R. Pain - Clinical updates - Pain depression. Seattle: IASP Press; 1994

49. Magni G, Caldieron C, Rigatti-Luchini S, Merskey H. Chronic musculoskeletal pain and depressive symptoms in the general population. An analysis of the 1st National Health and Nutrition Examination Survey data. Pain 1990; 43:293-300.

50. Sullivan MJ, Reesor K, Mikail S, Fisher R. The treatment of the depression in chronic low back pain: review and recommendations. Pain 1992; 50:5-13.

51. Hirschfeld RM, Klerman GL, Andreasen NC, Clayton PJ, Keller MB. Situational major depressive disorder. Arch Gen Psychiatr 1985; 42:1109-1114

52. Fishman SM, Greenber D. Psychosocial issues in the treatment of pain. In: Borssk D, LeBel AA, McPeek B (eds). The Massachussetts General Hospital Handbook of Pain Management. New York: Little Brown; 1996. p.379-393.

53. Bradley JJ. Severe localized pain associated with the depressive syndrome. Br J Psychiatr 1963; 109:741-745

54. Lindsay P, Wyckoff M. The depression pain syndromes and its response to antidepressants. Psychosomatics 1981:22:571-577.

55. Von Knorring L, et al. Pain as a symptom in depressive disorders. I. Relationship to diagnostic subgroup and depressive symptomatology. Pain 1983; 15:19.

56. Ward NG. Pain and depression. In: Bonica JJ (ed). The Management of pain. Philadelphia: Lea \& Febiger; 1990. p. 310-319.

57. Kramlinger KG, Swanson DW, Maruta T. Are patients with chronic pain depressed? Am J Psychiatr 1983; 140: 747-749.

58. Maruta T, Vatterott MK, Mchardy MJ. Pain management as an antidepressant: long-term resolution of pain-associated depression. Pain 1989, 36:335-337.

59. Breitbart W. Psychiatric management of cancer pain. Cancer 1989; 63(Suppl) 2336-2342

60. Bond MR. Cancer pain: psychological substrates and therapy. In: Fields $\mathrm{HL}$ Dubner R. Cervero F. Advances in pain research and therapy: proceedings of the Fourth World Congress on Pain. New York: Raven Press; 1985; p.559-567.

61. Coyle N. Characteristics of advanced cancer as terminall illness. J Pain Symp Man. 1990; 5:83-93

62. Body JJ, Weissman MM. Epidemiology of affective disorders. A reexamination and future directions. Arch Gen Psychiatr 1981; 38:1039-1046.

63. Sociedade Brasileira de Psiquiatria Clínica. Depressão em atenção primária: detecção, diagnóstico e tratamento. Ribeirão Preto; 1994

64. Clark DC, Cavanaugh SA, Gibbons RD. The core symptoms of depression in medical and psychiatric patients. J Nerv Ment Dis 1983; 171: 705-713.

65. Wells KB, Golding JM, Burnam MA. Psychiatric disorder in a sample of the general population with and without chronic medical conditions. Am Psychiatr 1988; 45:976-981.

66. Van Houdenhove B, Onghena P. Depression and physical illness. In: Robertson MM, Katona CLE (eds). Wiley: Chichester; 1997. p. 465-497.

67. Dworkin RH, Richlin DM, Handlin DS, Brand L. Predicting treatment response in depressed and non-depressed chronic pain patients. Pain 1986; 24:343-353.

68. Herr KA, Mobily PR. Interventions related to pain. Nurs Clin North Am 1992 27: 347-369.

69. Spiegel D, Bloom JR. Pain in metastatic breast cancer. Cancer 1983 52:341-345

70. Buckerg J. Penman D. Holland JC. Depression in hospitalized cancer patients. Psychosom Med 1984; 46:199-212.

71. Costa-Pires MEB. Contribuição para o estudo do estado depressivo: desenvolvimento de um questionário para sua avaliação [dissertação]. Ribeirão Preto: Escola de Enfermagem de Ribeirão Preto da UUniversidade de São Paulo; 1984.

72. Herry KA, Mobily PR. Interventions related to pain. Nurs Clin North Am 1992; 27: 347-369.

73. Fishbain DA, Rosomoff HL, Rosomoff RS. Types of pain treatment facilities and referral selection criteria: a review. Arch Fam Med 1995; 4:58-66

74. Leino P, Magni M. Depressive and distress symptoms as predictors of low back pain, neck-shoulder pain, and other musculoskeletal morbidity: a 10year follow-up of metal industry employees. Pain 1993; 53: 89-94.

75. Von Korff A, Dworkin SF, Le Resche L, Kruger A. An epidemiologic comparison of pain complaints. Pain 1988; 32:173-183

76. Merskey $\mathrm{H}$. The effect of chronic pain upon the response to noxious stimuli by psyhiatric patients. J Psychosom Res 1965; 8:405-419.

77. Pikoff $\mathrm{H}$. Is the muscular model of headache still viable? A review of conflicting data. Headache 1984; 24:186-198.

78. Nouwen A, Bush C. The relationship between paraspinal EMG and chronic low back pain. Pain 1984; 20:109-123.

79. Stahl SM. Psicofarmacologia dos antidepressivos. Reino Unido: Martin Dunitz; 1997. p. 3-38

80. Almay BG, Johansson F. Von Knorring L. Terenius L. Wahlstrom A. Endorphins in chronic: I Differences in CSF endorphin levels between organic and psychogenic pain Syndromes. Pain 1978; 5:153-162.

81. Blumer D, Heilbronn M. Chronic pain as a variant of depressive disease, the pain-prone disorder J Nerv Ment Dis 1982; 170:381-406.
82. Yaksh TL, Wilson PR. Spinal serotonin terminal system mediates antiociception. J Pharmacol Exp Ther 1979: 208:446-453.

83. Yaksh TL, Ramana RSV. Studies in the primate on the analgesic effects associated with intrathecal actions of opiates, adrenergic agonists and baclofen. Anesthesiol 1981; 54:451-467.

84. Weiss JM, Simson PG. Neurochemical basis of stress-induced depression. Psychopharmacol Bull 1985; 21:447-457.

85. Sternbach RA. The need for an animal model of chronic pain. Pain 1976; 2: 2-4

86. Ward NG, Kokan JA, Ang J, Butler SH. Differential effects of fenfluramine and dextroamphetamine on acute and chronic pain. In: Fields HL, Dubner R, Cervero $\mathrm{F}$ (eds). Advances in pain research and therapy. Proceedings of the Fourth World Congress on Pain. New York: Raven Press; 1985. p. 753-760

87. Sulser F. Molecular mechanisms in antidepressant action. Psychopharmacol Bull 1983; 19: 300-304.

88. Ghia JN, Mueller RA, Duncan GH, Scott DS, Mao W. Serotonergic activity in man as a function of pain, pain mechanisms, and depression. Anesth Analg 1981;60:854-861.

89. Oliveira IR, Moreira EC. Manual de psicofarmacologia clínica. Rio de Janeiro: Medsi, 1996; p. 103-147.

90. Magni G. On the relationship between chronic pain and depression when there is no organic lesion. Pain 1987; 31:1-21.

91. Engle GL. "Psychogenic" pain and the pain-prone patient. Am J Med 1959 26:899-918.

92. Akiskal HS, McKinney WT. Overview of recent research in depression. Arch Gen Psychiatr 1975; 32:285-305.

93. Hendler N. Depression caused by chronic pain. J Clin Psychiatr 1984; 45: 30

94. Rudy T, Kerns RD, Turk DC. Chronic pain and depression: toward a cognitive-behavioral mediation model. Pain 1988; 35:129-140.

95. Herr KA. Chronic pain and depression: testing a cognitive-behavioral mediation model. In: Biennal Convention Nursing Challenge Leadership in Changing Times. Abstracts. Indianapolis: Sigma Theta Tau International 1993. p.244.

96. Atkinson JH, Ingram RE Jr, Kremer ER, Saccuzzo DP. MMPI subgroups and affective disorder in chronic pain patients. J Nerv Ment Dis 1986; 174:408-413.

97. Abbey SE, Garfinkel PE. Chronic fatigue syndrome and depression: Cause effect or covariate? Rev Infect Dis 1991; 13(Suppl 1): S73-S83.

98. Gerber PD, Barret JE, Barret JA, Oxman TE, Manheimer E, Smith R, et al. The relationship of presenting physical complaints to depressive symptoms in primary care patients. J Gen Intern Med 1992; 7: 170-173.

99. Kittelberger KP, LeBel AA, Borsook D. Assessment of pain. In: Borssk D, LeBe AA, McPeek B (eds). The Massachussetts General Hospital Hándbook of Pain Management. New York: Little Brown; 1966. p. 40

100.Ramamurthy S, Rogers JN. Decision Making in Pain Management. In: Decker ABC (ed). Ney York: Mosby Year Book; 1993.

101. Caudill M. Controle a dor antes que ela assuma o controle. São Paulo: Summus Editorial; 2001.

102.Catalano EM, Hardin KN. Dores Crônicas. São Paulo: Summus Editorial; 2003.

103.Candeletti S, Romualdi P, Spadaro C, Spampinato S. Ferri S. Studies on the antinociceptive effect of intrathecal salmon calcitonin. Peptides 1985; 6: 273-276.

104.Amano N, Hu JW, Sessle BJ. Responses of neurons in feline trigeminal subnucleus caudalis (medullary dorsal horn) to cutaneous, intraoral and muscle afferent stimuli. J Neurophysiol 1986; 55:227-243.

105.Bennett DL, Michael GJ, Ramachandran N, Munson JB, Averill S, Yan $Q$, et al. A distinct subgroup of small DRG cells express GDNF receptor components and GDNF is propecive for these neurons after nerve injury. $J$ Neurosci 1998; 18:3059-3072.

106. Koenig TW, Clark M. Advances in Comprehensive pain management. Psychiatric Clin North Am 1996; 19:589-611.

107. Markowitz JS, Patrick KS. Venlafaxine- tramadol similarities. Med Hypotheses 1998; 51:167-168.

108.Schreiber S, Backer MM, Pick CG. The antinociceptive effect of venlafaxine in mice is mediated throough opioid and adrenergic mechánisms. Neurosci Lett 1999: 273:85-88.

109. Cortet B, Houvenagel E, Forzy G, Vincent G, Delcambre B. Evaluation of the effectiveness of serotonin (fluoxetine hydrochloride) treatment. Open study in fibromyalgia. Rev Rhum Mal Osteoartic 1992; 59:497-500.

110.Wolfe F, Cathey MA, Háwley DJ. A double-blind placebo controlled trial of fluoxetine in fibromyalgia. Scand J Rheumatol 1994; 23:255-259.

111.Rani PU, Naidu UM, Prasad VB, Rao TR, Shobhá JC. An evaluation of antidepressants in rheumatic pain conditions. Anesth Analg 1996; 83:371-375.

112. Goldenberg D, Mayskiy M, Mossey C, Rutházer R, Schmid C. A randomized double-blind crossover trial of fluoxetine and amitripytine in the treatment of fibromyalgia. Arthritis Rheum 1996; 39:1852-1859.

113.Bank J. A comparative study of amitriptyline and fluoxamine in migraine prophylaxis. Headache 1994; 34:476-478

114.Schreiber S, Backer MM, Yanai J, Pick CG. The antinociceptive effect of fluvoxamine. Eur Neuropsychopharmacol 1996; 6:281-284

115. Nascimento ED. Prophylaxis of migraine: open study venlafaxine in 42 patients. Arq Neuropsiquiatr 1998; 56:744-746.

116.Atkinson JH, Slater MA, Wahlgren DR, Williams RA, Zisook S, Pruitt SD, et al. Effects of noradrenergic and serotonergic antidepressants on chronic low back pain intensity. Pain 1999; 83:137-145.

117.Deyo RA. Fads in the treatment of low back pain. N Eng J Med 1991 $325: 1039-1040$ 